\title{
OVARIAN CALCIFICATION MIMICKING VESICLE CALCULUS
}

Pallavi Agrawal, Pratibha Singh, Santosh Kumar Agrawal, Neeeta Natu, Kamal Malukani

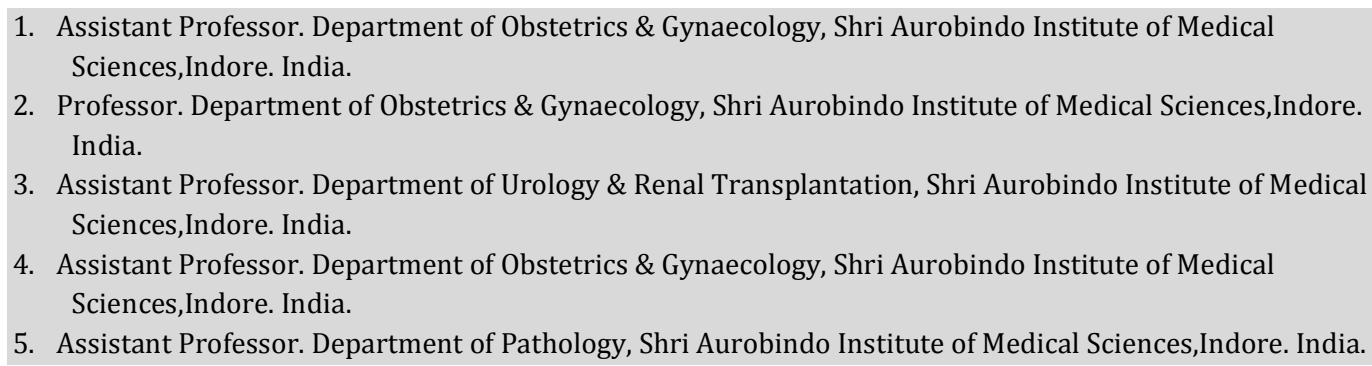

5. Assistant Professor. Department of Pathology, Shri Aurobindo Institute of Medical Sciences,Indore. India.

\section{CORRESPONDING AUTHOR:}

Dr. Pallavi Agrawal,

Flat No. 701, Aadarsh Building, SAIMS Campus,

Indore Ujjain Highway, Indore.

E-mail: agrawalpallavi@rocketmail.com

INTRODUCTION: Calcification in ovary is usually dystrophic in nature, forming secondary to degeneration of the epithelium or in association with areas of necrosis. It may occur in cases of endometriosis ${ }^{[1]}$ or in some ovarian tumor eg. Fibro thecoma [2], Brenner's tumor ${ }^{[3]}$, cavernous hemangioma[4] etc. Benign unilateral densely calcified ovary without any association with tumor or endometriosis has not been reported previously. We report a case of heavily calcified left ovary which mimicked as vesicle calculus on X-ray leading to confusion in diagnosis.

CASE REPORT: A 65 years old female came with complaint of something coming out of vagina, pain in back. She had to deposit the mass before micturition. On examination it was $3^{\text {rd }}$ degree uterovaginal descent with cystocele and rectocele. Blood investigations including serum calcium, inorganic phosphate and serum parathyroid hormone level were within normal limit. Ultrasonography showed cholelithiasis and bilateral mild hydroureteronephrosis.

Abdominal x-ray was done for low back pain which reported severe osteoporosis and dense radio opaque shadow of size $4 \mathrm{cmsx} 3 \mathrm{cms}$ in left hemipelvis possibly suggestive of vesical calculus (Figure 1). After consultation with urologist, patient was planned for vaginal hysterectomy with cystoscopy followed by cystolithotripsy. During surgery, after completion of vaginal hysterectomy, we tried to palpate the stone in the urinary bladder but could not palpate. On further examination, hard stone was felt posteriorly in peritoneal cavity and was brought out through introitus. The stone was attached with vascular pedicle (Figure 2) on further exploration it was confirmed that it was calcified left ovary with ovarian pedicle attached to it. There was no other mass associated with this finding. Pedicle was doubly ligated and calcified ovary was removed. Procedure concluded with pelvic floor repair. Histopathology report showed heavy calcification with necrotic stroma.

DISCUSSION: Small calcification 1-3 $\mathrm{mm}$ is frequent finding in ultrasonography and usually benign in nature [5]. Larger calcification $5-13 \mathrm{~mm}$ also usually have benign course if associated mass lesion is excluded in imaging and probably may not need prolonged followup [5]. Larger calcifications may be associated with many type of ovarian tumor and chocolate cyst of 
endometriosis. Cystadenocarcinoma of ovary and dermoid cyst of ovaries are the most common tumor associated with calcification[5]. Dense calcification have also been described in cases of fibrothecoma [2], Brenner's tumor ${ }^{[3]}$, cavernous hemangioma of ovary ${ }^{[4]}$. Benign chocolate cyst of ovarian endometriosis may develop dense stone like calcification due to osseous metaplasia [1]. In, all of the above cases patients are symptomatic due to ovarian tumor or endometriosis.

Although there is report of bilateral benign calcified ovaries in literature [6], this type of unilateral calcification without any association with tumor or endometriosis has not been reported. It was mistaken with bladder stone due to USG showing bilateral hydronephrosis and $\mathrm{X}$-ray pelvic calculus. This type of asymptomatic ovarian calculus has been reported in children following torsion of ovary leading to necrosis and calcium deposit followed by autoamputation of ovary known as wandering ovary [7].

To summarize we are reporting a calcified ovary which initially confused with bladder stone.

\section{REFERENCE}

1. Su WH, Wang PH, Chang SP. Ovarian stone. A case report. J Reprod Med 2002 Apr;47:32931.

2. Mak CW, Tzeng WS, Chen CY. Computed tomography appearance of ovarian fibrothecomas with and without torsion. Acta Radiol. 2009 Jun;50:570-5.

3. Moon WJ, Koh BH, Kim SK, Kim YS, Rhim HC, Cho OK, Hahm CK, Byun JY, Cho KS, Kim SH. Brenner tumor of the ovary: CT and MR findings. J Comput Assist Tomogr. 2000 JanFeb;24:72-6.

4. Kimmy,Rhase,Ohsn et al. Ovarian cavernous hemangioma presenting as heavily calcified adnexal mass. British Journal of Radiology 2008; 81: 269-71.

5. Brown DL, Laing FC, Welch WR. Large calcifications in ovaries otherwise normal on ultrasound. Arch Pathol Lab Med. 1992 Feb;116:204-5.

6. Keshtgar AS, Turnock RR. Wandering calcified ovary in children. Pediatr Surg Int 1997;12:215-16.

7. Clement PB, Cooney TP. Idiopathic multifocal calcification of the ovarian stroma. Arch Pathol Lab Med 1992;116:204-5. 


\section{CASE REPORT}

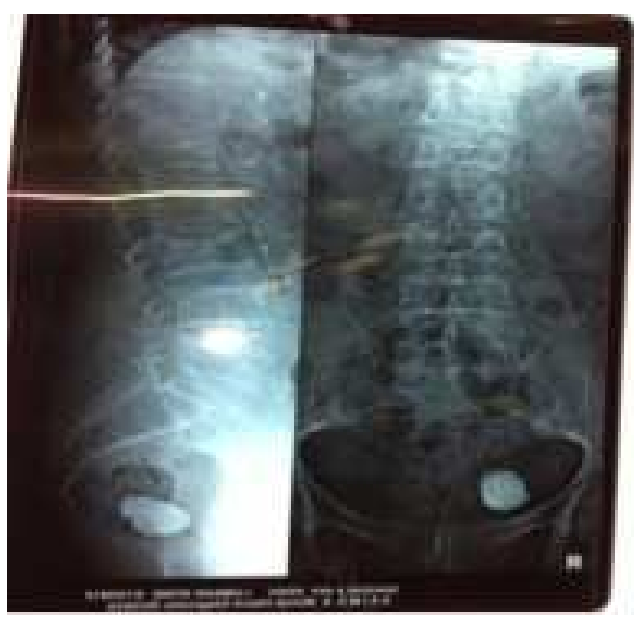

Figure 1: X-ray showing dense radio opaque shadow in left hemi pelvis reported as a vesicle calculus

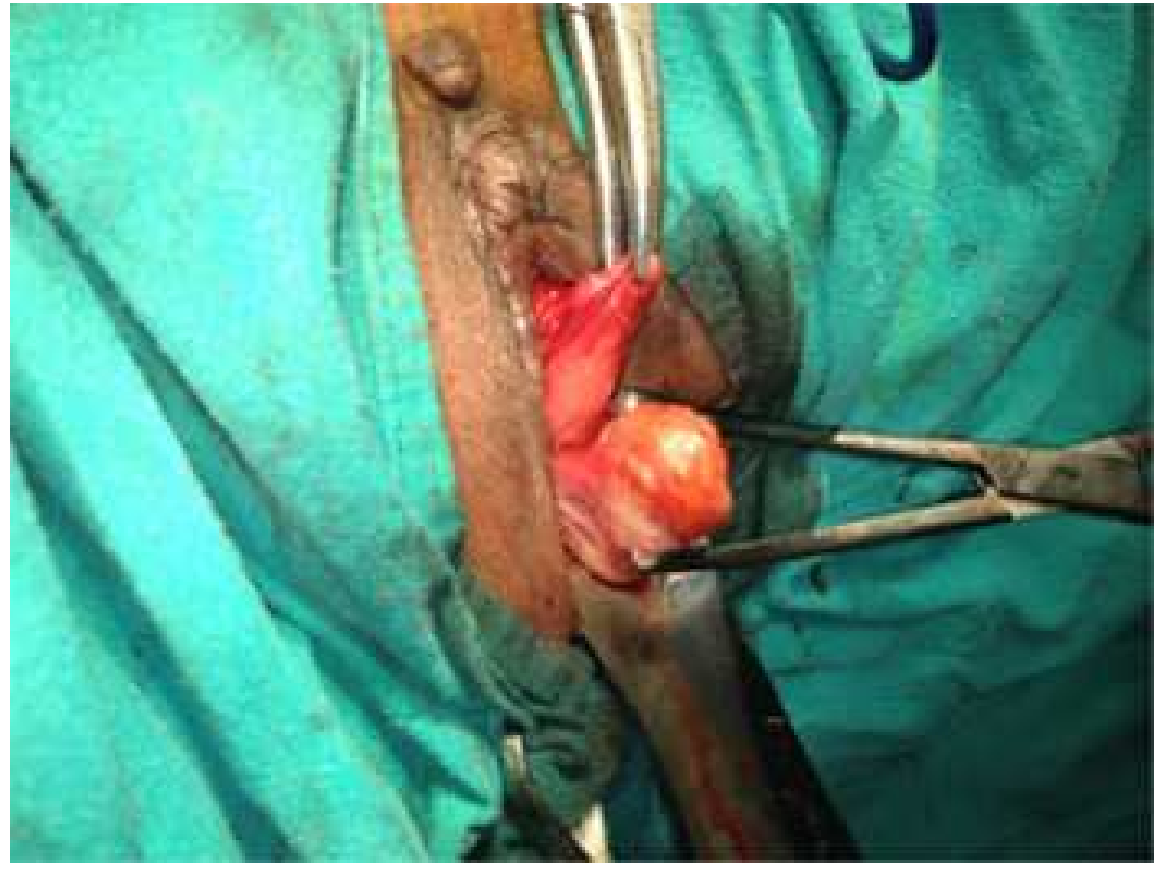

Figure 2: Calcified ovary attached with vascular pedicle. 